\title{
O CARÁTER CONTINUÍSTA DO DISCURSO OFICIAL SOBRE CONFIGURAÇÃO DE UM SUJEITO DOCENTE PARA O TRABALHO COM A LEITURA LITERÁRIA NO ENSINO MÉDIO DO SÉCULO XXI
}

\author{
Rodrigo Alves dos Santos \\ ralves@div.cefetmg.br
}

Primeiras palavras...

O presente artigo se detém sobre os Parâmetros Curriculares Nacionais do Ensino Médio (PCN) e alguns dos documentos dele derivados, especificamente no que se referem à componente curricular de Língua Portuguesa.

Desenvolve-se, aqui, o argumento de que uma leitura analítica desses documentos oficiais permite constatar um caráter de continuidade no discurso que vem configurando o modo de existência docente propalado desde a virada do milênio pelo discurso regulador e configurador da formação e da atuação do professor do chamado novo Ensino Médio, no que ele se refere à formação e a atuação do professor de Língua Portuguesa para o trabalho com a leitura literária.

Os documentos eleitos como objeto de pesquisa para esta reflexão (os PCN, os PCN+e as Orientações Curriculares Nacionais), cada qual a seu modo, terminaram por tratar da indicação de conteúdos, de formas de abordagem dos temas e assuntos tratados, de opções metodológicas de ensino, de suportes teóricos autorizados, de conceitos a serem fixados, 
de saberes e comportamentos a serem “ensinados", de sujeitos pedagógicos desejados e, ainda, de formas comportamentais prescritas para esses sujeitos, fossem eles professores ou alunos. Nesse sentido, inscreveramse rapidamente na discursividade da Educação, campo que constitui, há tempos, uma forma eficaz "de manter e modificar a apropriação dos discursos, com os saberes e os poderes que eles comportam" (FOUCAULT, 1996, p.43-44). Exatamente por isso, esses documentos tiveram (e ainda têm) capital importância na constituição do que veio se configurando como parâmetro do que se espera em relação à atuação do professor de língua portuguesa que aborda a leitura no ensino médio, à formação técnico-pedagógica desse professor e à formação literária oferecida ao público juvenil.

Diferentemente das abordagens feitas nos trabalhos já realizados sobre os documentos acima nomeados (Cf. p.ex. FREITAS 2003 e 2007; LEAHY in PAULINO e COSSON, 2004; ZINANI e SANTOS in PAULINO e COSSON, 2004), neste artigo, o discurso neles veiculado é considerado como uma prática (FOUCAULT, 1995a, 1996). Isso significa que ele é tomado não como representação das coisas, dos objetos, dos sujeitos de que trata, mas como espaço de produção deles. Em sendo assim, seguindo na direção apontada pelos deslocamentos feitos pelo filósofo francês Michel Foucault no trato com o discurso e também por reflexões sobre a análise de discursos sob uma perspectiva foucaultiana (ALMEIDA, 2006; FISCHER, 2001; GREGOLIN, 2007; PARAÍSO, 2007; SARGENTINI, NAVARRO-BARBOSA, 2004), opera-se, neste trabalho, uma análise que busca significar não o que o discurso nele veiculado oculta, mas sim o que produz, fabrica quando trata da formação e atuação dos professores de Língua Portuguesa para o trabalho com a leitura literária no chamado novo Ensino Médio.

Nessa "outra maneira de abordar as performances verbais", ainda de acordo com a proposta de Foucault (1995a, 1996), deve-se considerar que "o discurso funciona como um sistema de controle, seleção e exclusão de enunciados; mas também de sua produção, sua reativação e recriação" (PARAÍSO, 2007, 67). Sendo limitados e raros, conforme as teorizações do filósofo francês, os enunciados, nessa perspectiva, não constituem em si mesmo uma unidade, "mas sim [...] uma função que cruza o domínio de estruturas e de unidades possíveis e que faz com que apareçam conteúdos concretos no tempo e no espaço" (Foucault, 1995a, p.99) e que, conforme sistematiza Fischer (2001), a partir das teorizações foucaultianas (1995a), caracterizam-se por quatro elementos básicos: 
um referente (ou seja, um princípio de diferenciação), um sujeito (no sentido de posição a ser ocupada), um campo associado (isto é, coexistir com outros enunciados) e uma materialidade específica - por tratar de coisas efetivamente ditas, escritas, gravadas em algum tipo de material, passíveis de repetição ou reprodução, ativadas através de técnicas, práticas e relações sociais (FISCHER, 2001, p. 202)

Assim sendo, como se verá mais adiante, o discurso sobre a formação e atuação do professor de Língua Portuguesa, no que se refere ao trabalho com a leitura literária desejado para o novo Ensino Médio, é analisado nesta investigação com vistas à identificação do(s) enunciado(s) nele ativado(s).

Em relação ao(s) enunciado(s) identificado(s), a análise aqui realizada procura destacar aqueles que se referem à formação e à atuação do professor de Língua Portuguesa para o trabalho com a leitura literária no novo Ensino Médio, interesse central deste trabalho.

\section{O discurso dos PCN e de alguns dos seus derivados no que se referem à abordagem do texto literário no ensino médio: configuração de um modo de ser docente.}

A centralidade do professor como agente de uma mudança na educação formal é o enunciado mais recorrente no discurso veiculado nos PCN, nos $\mathrm{PCN}+$ e nas Orientações Curriculares que são objeto desta reflexão.

Trata-se de um enunciado que é ativado na materialidade discursiva em causa, mas que está situado no campo do discurso pedagógico. Nesse sentido, verifica-se uma franca continuidade com o discurso crítico em educação o qual, como afirma Paraíso (2007), fundamentou propostas pedagógicas "de grande repercussão no campo educacional nos anos 1980 e, ainda hoje, sustentam políticas educacionais e reformas curriculares nos diferentes níveis de ensino no Brasil" (PARAÍSO, 2007, p.73). Conforme afirma Garcia (2002):

O esclarecimento das consciências com as verdades propiciadas pela ciência e pela (auto-reflexão). O acesso a formas superiores de pensamentos e existência individual e social. A produção do sujeito ou do cidadão racional [...] (auto-) reflexivo e autônomo, ou seja, sujeito ou classe social plenamente desenvolvidos. A redenção e salvação de si mesmo e da humanidade pelo poder libertador da razão e da ação (agência humana) sintetizam os enunciados de pedagogias que se auto-intitulam pedagogias revolucionária, sócio-histórica, histórico-crítica, crítico-social dos conteúdos, libertadora, da conscientização, da autonomia e da esperança, quando tratam das finalidades, das metas ou da teleologia da educação e do trabalho didático-pedagógico-crítico e progressista (GARCIA, 2002, p. 35). 
Assim, marcas desse discurso crítico em educação estão presentes no que é veiculado nos PCN e em seus derivados, quando se ativa o enunciado da centralidade do professor como agende de uma mudança na educação formal. Evidencia disso já se nota na Carta ao professor que abre os Parâmetros Curriculares Nacionais de Língua Portuguesa, quando o docente é tomado como interlocutor do então Ministro da Educação, Paulo Renato de Souza:

os Parâmetros Curriculares Nacionais para o Ensino Médio são o resultado de meses de trabalho e discussão realizados por especialistas e educadores de todo o país. Eles foram feitos para auxiliar você, professor, na execução do seu trabalho. Servirão de estímulo e apoio à reflexão sobre a sua prática diária, ao planejamento de suas aulas e, sobretudo, ao desenvolvimento do currículo de sua escola, contribuindo para sua atualização profissional. Ao entregá-los a você, reafirmamos a nossa confiança na sua capacidade de atuar para transformar positivamente a educação em nosso País e aguardamos por novas contribuições e sugestões, que permitirão a revisão permanente destes documentos (BRASIL, 1999b, p. 11). [Grifos meus].

Ainda no mesmo documento, na Apresentação, assinada pelo então Secretário da Educação Média e Tecnológica, Ruy Leite Berger Filho, reitera-se a capacidade de agência do professor no processo de mudança desejado para a educação formal:

o Ensino Médio do Brasil está mudando. [...] Tínhamos um ensino descontextualizado, compartimentalizado e baseado no acúmulo de informações. Ao contrário disso, buscamos dar significado ao conhecimento escolar, mediante a contextualização; evitar compartimentalização, mediante a interdisciplinaridade; e incentivar o raciocínio e a capacidade de aprender. Estes Parâmetros cumprem o duplo papel de difundir os princípios da reforma curricular e orientar o professor, na busca de novas abordagens e metodologias. Ao distribuí-los, temos a certeza de contar com a capacidade de nossos mestres e com seu empenho no aperfeiçoamento da prática educativa (BRASIL, 1999b, p. 13). [Grifos meus]

Considerando os documentos originados a partir dos PCN do Ensino Médio, nos $\mathrm{PCN}+$ de Língua Portuguesa, também no início da publicação, reconhece-se o "papel central e insubstituível” dos professores "na condução e no aperfeiçoamento" (BRASIL, 2002, p.o7) do redirecionamento da Educação Básica orientado pela Lei de Diretrizes e Bases de 1996. Tal reconhecimento, por suavez, éreforçado nas Orientações Curriculares Nacionais para o Ensino Médio, com as quais se espera que o professor "aproveite estas orientações como estímulo à revisão de práticas pedagógicas, em busca da melhoria do ensino" (BRASIL, 2006, p. o6), nos anos finais da Educação Formal. 
Apesar de, em um primeiro plano, serem os documentos aqui analisados endereçados a uma pluralidade de leitores (gestores, professores, alunos e demais envolvidos tanto no processo de configuração do novo Ensino Médio, quanto no de regulação da atuação e da formação de professores) o professor é o interlocutor a quem, na maioria das vezes, o sujeito enunciador se dirige. Esse professor pelo qual se interessam os documentos acima não é apenas o docente em exercício, mas também aquele que está se preparando para o ingresso na docência na Educação Básica. Nesse sentido, fundamental foi a publicação do Decreto no 3.276 , de 6 de dezembro de 1999, que orientava que a formação de professores deveria ter como referência dos Parâmetros Curriculares. Isso porque, para o contexto de então, estavam dadas as prerrogativas legais para estender a vontade de mudança da Educação Formal também ao nível superior, alegando, com isso, que se estaria buscando uma formação de professores coerente com as transformações demandadas pelos novos entedimentos acerca da educação formal no país.

No que se referia ao trabalho com a leitura literária nos anos finais da chamada nova Educação Básica, o discurso veiculado nos documentos analisados fez aparecer, como sujeito para ocupar uma centralidade como agente de mudanças na Educação Formal do Brasil, o formador de leitores críticos de textos literários (BRASIL, 2006, p.72), assim nomeado pelas Orientações Curriculares para o Ensino Médio.

Para ocupar essa posição de sujeito, o professor de Língua Portuguesa, em exercício ou em formação, deveria, antes de tudo, estar consciente de que um diferente "projeto educacional" estava sendo posto em movimento no país, no que se referia aos anos finais da chamada nova Educação Básica. Logo, desejava-se, para a "nova escola" de Ensino Médio, um sujeito docente cujas práticas pedagógicas no trabalho com a leitura literária na disciplina de Língua Portuguesa não mais enfatizassem saberes, técnicas, métodos, ou compreensão de aprendizes privilegiados no antigo Segundo Grau. Como se lê nos PCN+ de Língua Portuguesa:

\footnotetext{
Os objetivos da nova educação pretendida são certamente mais amplos do que os do velho projeto pedagógico. Antes se desejava transmitir conhecimentos disciplinares padronizados, na forma de informações e procedimentos estanques; agora se deseja promover competências gerais, que articulem conhecimentos, sejam estes disciplinares ou não. Essas competências dependem da compreensão de processos e do desenvolvimento de linguagens, a cargo das disciplinas que, por sua vez, devem ser tratadas como campos dinâmicos de conhecimento e de interesses, e não como listas de saberes oficiais (BRASIL, 2002, p. 12). [Grifos meus]
} 
Para essa "nova educação pretendida", o sujeito docente desejado deveria ser consciente das (e atento às) especificidades do público jovem com o qual deveria interagir em sala de aula, pois:

cabe ao professor do ensino médio adquirir paulatinamente a consciência do público a quem se dirige seu discurso, levando em conta o fato de serem adolescentes, de trazerem uma bagagem de conhecimento adquirida ao longo do seu processo anterior de escolarização, de serem parte de um grupo social dotado de características próprias, que eventualmente os diferencia de outras comunidades (BRASIL, 2002, p. 75).

Além disso, pelo que se afirmava nos $\mathrm{PCN}+$ de Língua Portuguesa do Ensino Médio, "em um plano específico, mais diretamente ligado à disciplina Língua Portuguesa, percebe-se que o discurso oficial contemporâneo requer(ria) um profissional qualificado, e principalmente atualizado diante das teorias da linguagem que ganham espaço na escola" (BRASIL, 2002, p.85) (Grifos nossos). Logo, seria a esse perfil que deveriam se amoldar tanto o professor já atuante, quanto os indivíduos em formação para o exercício da docência a fim de ocupar a posição de formadores de leitores críticos de textos literários então desejada

Segundo o que se verifica no discurso analisado, a conversão do professor, demandado pelo "velho projeto pedagógico", ao almejado pela "nova educação pretendida" (BRASIL, 2002, p. 12) seria inquestionavelmente necessária, o que não queria dizer que fosse fácil de ser obtida, pois,

\footnotetext{
para o profissional que se encontra no mercado há algum tempo, algumas vezes torna-se difícil rever toda a sua formação e abrir-se para repensar o alcance real de sua prática.

(...)

Já os professores que acabam de entrar no mercado ressentem-se, em sua formação, das lacunas deixadas pelo ensino da língua pátria ao longo de seu próprio processo de escolarização. (BRASIL, 2002, p.85-86)
}

Mesmo assim, ainda conforme o discurso em questão, se se quisessem em consonância com as exigências dos novos tempos para a Educação Formal do país, os professores em exercício e os futuros docentes deveriam se comprometer com as mudanças desejadas, pois "a qualidade da escola é condição essencial de inclusão e democratização das oportunidades no Brasil" (BRASIL, 2006, Carta ao professor) e era preciso enfrentar "o desafio de oferecer uma educação básica de qualidade para a inserção do aluno" (id., ibid.).

Nessa "nova educação", o formador desejado de leitores críticos de textos literários seriaincondicionalmente umleitor. Exigênciaqueevidencia 
uma marcada continuidade do discurso veiculado nos documentos com aquele recorrente nas academias sobre a questão da leitura e da formação do leitor e que está em voga nos círculos universitários brasileiros desde os anos $1980^{1}$. Trata-se de uma necessidade propalada por professores e pesquisadores universitários respeitados no campo das Letras e da Educação, como Maria da Glória Bordini e Vera Teixeira de Aguiar. Essas, já então, alegavam que, se a escola quisesse de fato

um ensino eficaz da leitura da obra literária, deve[ria] cumprir requisitos como: dispor de uma biblioteca bem aparelhada, na área de literatura, com bibliotecários que (...) [promovessem] o livro literário, professores leitores com boa fundamentação teórica e metodológica, programas de ensino que (...) [valorizassem] a literatura e (...) uma interação democrática e simétrica entre o alunado e o professor (AGUIAR; BORDINI, 1988, p. 17)" (Grifos meus).

No discurso materializado nos PCN+ de Língua Portuguesa e nas Orientações Curriculares para o Ensino Médio, essa condição de leitor do formador de leitores críticos de textos literários era associada à realização de uma ruptura, por parte do professor de Português que viesse a ocupar uma centralidade como agente de uma mudança da educação formal do país. Tal ruptura relacionava-se com a superação do entendimento de que a literatura que deveria "entrar na escola" seria apenas a eleita por aqueles que construíam o cânone escolar.

Nessa "nova escola” de Ensino Médio desejada, "o educador não tem o direito de ignorar a condição extraescolar do educando" (BRASIL, 2002, p. 12). Opinião que, por sua vez, evidenciava uma continuidade do discurso acadêmico sobre a questão da leitura e da formação do leitor divulgado no Brasil. Discurso esse veiculado a partir dos anos 1990, quando estudiosos do assunto já falavam, ao problematizarem os usos da literatura na aula de Língua Portuguesa, em: "necessidadedeesgarçaras fronteirasentreo literário e o não-literário" (CURY in.: PAULINO; WALTY, 1994), "importância da opinião dos jovens leitores na definição de obras que comporiam o cânone escolar" (PAULINO, 1999), relevância de se considerar as "apropriações que os leitores realmente fazem" (EVANGELISTA, 2006).

\footnotetext{
${ }^{1}$ Essa discussão se insere no debate da então nomeada crise no ensino da leitura, a qual põe foco no que desde então foi nomeado como ineficácia do ensino da leitura da literatura no Brasil. Trata-se de um debate que já vem se estendendo por décadas, contando com a contribuição de obras como as elaboradas e/ou organizadas por Leite (1983), Silva (1983), Zilberman (1986, 1988), Aguiar e Bordini (1988), Paulino e Walty (1994), Soares (in.: MARTINS, BRANDÃO, MACHADO, 1999), Lajolo (2001, 2002), Geraldi (2003), Paulino e Cosson (2004), Cosson (2007), com boa parte das quais os documentos reguladores e configuradores do trabalho com a leitura literária no Ensino Médio mantêm um assumido diálogo.
} 
Mas, mesmo que tivesse que considerar o que conhece e o que lê o educando no universo extraescolar, reconhece-se, na materialidade discursiva aqui considerada, que ao formador de leitores críticos de textos literários caberia, ainda, o desafio de levar

o jovem à leitura de obras diferentes desse padrão [das obras consagradas pela mídia e com linguagem próxima dos discentes] - sejam [fossem] obras da tradição literária, sejam [fossem] obras recentes, que tenham sido legitimadas como obras de reconhecido valor estético - , capazes de propiciar uma fruição mais apurada, mediante a qual terá acesso a uma outra fortuna de conhecimento de si e do mundo (BRASIL, 2006, p. 70).

Além dos predicados até aqui mencionados, o formador de leitores críticos de textos literários, deveria, ainda, ser um sujeito tecnológico, pois

é comum que o aluno [da Educação Básica] entre em contato com as tecnologias da informação fora e não dentro da escola. Elas são indissociavelmente ligadas ao cotidiano da maioria dos jovens e, por isso, é importante que a escola mostre como ler, de forma crítica e consequente, o que é veiculado por meio delas. (BRASIL, 2002, p. 69-70).

Em uma continuidade da discursividade da valorização das tecnologias da informação e comunicação (TIC), a qual vem ganhando destaque no campo educacional ${ }^{2}$, o que se espera do sujeito docente então objetivado é que ele use com equilíbrio ("nem pouco, nem muito") da tecnologia (Cf. BRASIL, 2002, p. 88). Esta, nesse sentido, deveria ser aproveitada pelo professor de Língua Portuguesa tanto durante as aulas (editores de texto, cds, tvs, dvds, formas de comunicação a distância etc. Cf. BRASIL, 2002 e 2006), quanto no preparo delas e nas pesquisas que se esperava que ele fizesse para prepará-las, pois "apesar da resistência dos muitos que se formaram fora dessa cultura, as modernas tecnologias sem dúvida têm muito a oferecer nesse sentido (BRASIL, 2002, p.89)".

Para além dos aspectos já elencados, ao formador de leitores críticos de textos literários objetivado no discurso aqui estudado caberia, ainda, o papel de "mediador cultural", como se defendeu nas Orientações Curriculares para o Ensino Médio:

${ }^{2}$ ALMEIDA (2006), em tese de doutorado defendida na Faculdade de Psicologia e Ciências da Educação da Universidade do Porto, Portugal, faz um interessante trabalho de investigação no qual procura defender o argumento de que, com discursividade de valorização das TIC na educação, o campo educativo e seus atores passam a ser reconfigurados em um novo regime de verdade. 
o estatuto do leitor e da literatura, no âmbito dos estudos literários, leva-nos a dimensionar o papel do professor não só como leitor, mas como mediador, no contexto das práticas escolares de leitura literária (BRASIL, 2006, p. 72). [Grifos meus]

Introduzida no campo das Letras a partir dos estudos de Linguística e de Comunicação (Cf. Costa, 2009), a noção de mediação cultural usada nesse discurso se afina com a dos estudos do campo da antropologia, área na qual autores como Eric Wolf (in Willigen, 1993, p. 127) empregam o termo mediador cultural para se referir "à pessoa que funciona como elemento de ligação entre dois sistemas culturais (id., ibid.)".

$\mathrm{Na}$ materialidade discursiva considerada neste trabalho, sobretudo nas Orientações Curriculares para o Ensino Médio, a compreensão do professor como mediador decorre do entendimento de que, na disciplina de Língua Portuguesa do novo Ensino Médio, a leitura é entendida como prática cultural - noção, por sua vez, buscada em Chartier (1994, 1997). Desse modo, conforme o que consta nos PCN+ e nas Orientações Curriculares Nacionais para o Ensino Médio, sendo as leituras, em sala de aula, sempre plurais, ao formador de leitores críticos de textos literários caberia uma função mediadora, em dois sentidos. Uma primeira estaria relacionada ao fato de o docente se colocar "entre" as muitas significações produzidas pelos alunos. Nesse sentido, o professor seria, conforme se afirma nos $\mathrm{PCN}+$, por exemplo, o responsável pela sistematização das muitas leituras produzidas pelos alunos, de modo a chegarem a um rol de significações possíveis eaceitáveis para um texto trabalhado. Uma segunda, da qual trata Evangelista (200o), estaria relacionada ao fato de os docentes estarem "entre os seus alunos-leitores e as obras literárias, conhecendo uns e outras - os interesses (variados) dos alunos e a potencialidade (múltipla) das obras-, para promover esse encontro, ressaltando a importância das predisposições iniciais dos próprios leitores como ponto de partida para o alargamento do seu universo de leituras" (Cf. EVANGELISTA, 2000, p. 248). Evidencia-se, portanto, mais uma vez, no discurso aqui analisado, mais uma marca de continuidade.

Para desempenhar, da forma então desejada, a função para ele indicada, o formador de leitores críticos de textos literários deve ser, ainda, um pesquisador. Essa "atitude investigativa" constituiria, segundo consta nos $\mathrm{PCN}+$ e nas Orientações Curriculares Nacionais, um dos principais pontos que poderiam garantir ao formador de leitores críticos de textos literários a atualização tão desejada e considerada uma condição para que o sujeito docente viesse a ocupar uma centralidade como agente de uma mudança na Educação Formal do país (Cf. BRASIL, 1999b, 2002, 2006). 
Também essa condição de pesquisador demandada para o professor de Língua Portuguesa para o trabalho com a leitura literária constitui uma marca de continuidade de posicionamentos manifestados no discurso acadêmico tanto das Letras, quanto da Educação, nacional ou internacionalmente. No primeiro caso, nomes como o do professor universitário e pesquisador português Carlos Ceia são categóricos em assumir que, para a realização de um trabalho produtivo com a literatura na escola, "o professor de literatura tem que ser, em primeiro lugar, um investigador de literatura (...) (CEIA in. MELLO; et.al. 2002, p. 35). Já no campo da Educação, a condição de pesquisador e sua relevância no processo de formação e atuação do professor vêm, já há algum tempo, sendo defendida por nomes, como Garcia (1994; 1999), Gauthier et.al. (1998), Nóvoa (1992), Buarque (2000); Demo (2003) Diniz-Pereira (2006) e considerada essencial para a promoção de mudanças nos processos educativos de alguns países, segundo documentos publicados por organismos internacionais (Cf. DELORS, 2001; 2005).

Consciente das especificidades do público jovem com o qual interagiria nas aulas, qualificado, atualizado, tecnológico, pesquisador, leitor crítico, não preconceituoso (já que compreenderia e respeitaria as leituras extraescolares dos aprendizes), mediador cultural... seriam essas as atribuições do sujeito docente objetivado no discurso da materialidade discursiva aqui analisada no que se referiu ao trabalho com a leitura literária nos anos finais da nova Educação Básica. Tais atributos constituiriam o perfil do sujeito docente demandado, ou desejável, para indivíduos que almejam ocupar uma centralidade como agente de mudanças na educação formal do país.

Porém, o discurso sobre a formação e a atuação do professor de Língua Portuguesa divulgado na materialidade aqui estudada não se limitava apenas a descrever o perfil do novo sujeito docente a ocupar tal posição no chamado novo Ensino Médio,ambém seriam divulgadas ações e estratégias didáticas que o formador de leitores críticos de textos literários deveria executar/operacionalizar a fim de cumprir bem a sua desejada função. Nesse sentido, os PCN+ de Língua Portuguesa foram ricos em exemplificações, como se vê no quadro que segue:

Quadro 1: PCN+Ações que deveriam ser desenvolvidas pelo docente na bordagem no texto literário

\begin{tabular}{c|c}
\hline \multicolumn{1}{c|}{ Ação sugerida } & \\
\hline $\begin{array}{l}\text { Contextualização do texto a ser trabalhado em suas condições de produção } \\
\text { e também em relação às escolhas pictóricas e léxicas do autor. }\end{array}$ & p. 58 e 53 \\
\hline
\end{tabular}




\begin{tabular}{l|c}
\hline $\begin{array}{l}\text { Aproximação entre o texto literário de outros, construídos em linguagem } \\
\text { não-verbal, analisando os recursos expressivos de cada um com base em } \\
\text { critérios de semelhanças, diferenças ou especificidades. }\end{array}$ & p. 59 \\
\hline $\begin{array}{l}\text { Promoção de situações que permitam constatar a fragilidade deassociar os } \\
\text { conceitos de conotação e denotação à linguagem literária e não-literária, } \\
\text { respectivamente, sobretudo em relação a textos contemporâneos. }\end{array}$ & p. 6o \\
\hline $\begin{array}{l}\text { Apresentação de pontos em que os múltiplos gêneros que circulam no } \\
\text { universo literário (e/ou não literário) se aproximam e se afastam. Como }\end{array}$ & p. 63 \\
no caso das cantigas trovadoresca e dos cordéis nordestinos. & \\
\hline $\begin{array}{l}\text { Realização de situações de confronto de textos, explorando marcas } \\
\text { comuns e também diferenças entre escritos de um mesmo autor (ou entre }\end{array}$ & p.63 \\
textos de autores), sobretudo no trabalho com os estilos de época. & p. 65 \\
\hline $\begin{array}{l}\text { Promoção de situação de reflexão a partir de gêneros literários que } \\
\text { circulam socialmente, evidenciando que, quando comparados com os } \\
\text { textos literários, em muitos casos, aqueles se apropriam destes. }\end{array}$ & p. \\
\hline $\begin{array}{l}\text { Criação de situações em que o aluno tenha contato com produtos culturais } \\
\text { de toda ordem, de modo que o jovem conheça também manifestações } \\
\text { culturais com que não tenha um contato imediato. }\end{array}$ & p. 65 \\
\hline $\begin{array}{l}\text { Promoção de momentos voluntários para que os alunos leiam } \\
\text { coletivamente uma obra literária, assistam a filmes, leiam poemas da } \\
\text { própria autoria, de preferência fora da sala de aula. }\end{array}$ & p. 67 \\
\hline $\begin{array}{l}\text { Criação de projetos que propiciem a produção de totalidades } \\
\text { significativas, em diferentes linguagens artísticas, para posterior } \\
\text { exposição de produções. Ou seja, a partir de um mesmo tema gerador } \\
\text { (como o Barroco), reproduzir/criar ambientes, pinturas, músicas, textos } \\
\text { verbais e não verbais. }\end{array}$ & p. 68 \\
\hline $\begin{array}{l}\text { Promoção de situações em que os alunos possam analisar diferentes } \\
\text { abordagens de um mesmo assunto ou tema literário. }\end{array}$ & \\
\hline
\end{tabular}

As ações pedagógicas constadas nesse quadro constituem, também, uma continuidade com alguns discursos acadêmicos há muito divulgados em contexto nacional e estrangeiro, no que se referem ao trabalho esperado com a leitura literária em contexto escolar. Nesse sentido, o desejo de aproximar a literatura de outras formas de expressão artística ou de outras formas de realização da linguagem (WALTY, 2009a), "dessacralizando-a e democratizando-a" (ROSIER, 1993, p. 49), constitui, por exemplo, uma vontade que já há muito perpassa o discurso proveniente de estudos que buscaram integrar o campo das Letras ao da Educação. Vontade esta que deveria, segundo o discurso aqui analisado, ser considerada em um novo Ensino Médio no qual "a produção, a recepção e a circulação da literatura por quaisquer que sejam os públicos leitores [...] não podem ser estudadas como fenômenos isolados de 
outras produções culturais (BRASIL, 2002p. 61)”. Logo, em consonância com tal vontade acadêmica, estar-se-ia, com isso, atendendo a uma desejada aproximação entre "cultura, conhecimento e linguagem" para a promoção de "possíveis e pertinentes diálogos sobre a literatura e seu ensino ou suas mediações educativas na escola e na sociedade (MARTINS e CORREA in.: PAIVA et.al., 2007)".

Além dessas ações pedagógicas acima apresentadas, o discurso aqui analisado prescrevia (mesmo afirmando não ser este o seu desejo) outras ações, todas em consonância com o discurso acadêmico nacional e internacional. Uma delas dizia respeito ao fato de que o formador de leitores críticos de textos literários deveria procurar abandonar as aulas já montadas por críticos e estudiosos da literatura - os scripts, como chamaria Lajolo (2002, p. 15) - e romper com a tradição de abordar extratos de textos para investir, por exemplo, na leitura de obras integrais, conforme defendido por Houdart (1997, p.13). O interesse, com isso, seria o de atingir o desejado objetivo de "dotar o educando da capacidade de se apropriar da experiência literária" (BRASIL, 2006, p. 55), entendendo por isso a noção de "colocá-lo em contato efetivo com o texto literário" (id., ibid.), e de educar, por fim, o gosto do aprendiz³ (BRASIL, 2006, p.71).

A esse sujeito docente, de acordo com as Orientações Curriculares Nacionais, também competiria: 1) organizar sistematicamente o trabalho com a leitura em um projeto para os três anos do Ensino Médio; 2) considerar, na elaboração desse projeto, os gêneros e os autores que serão lidos pelos alunos, organizando-os por uma sequência lógica (não necessariamente cronológica); 3) ter sempre em consideração a necessidadedehaveruma margem paraleituras nãoprevistas, "anárquicas"4 ;4) terem mente uma noção de mobilidade do cânone literário, modificando as sequências de autores e obras sempre repetidos, sobretudo pelos livros didáticos; 5) ser capaz de retirar do programa da disciplina o que não for essencial; 6) não limitar o trabalho com o texto literário ao programa do vestibular (Cf. BRASIL, 2006, p. 72-80).

${ }^{3}$ Magnani (1989) constitui um dos nomes que, já na década de 1980, discutia a questão do papel da escola na formação do gosto da literatura pelo aprendiz. Para essa autora, "a escola, por sua vez, na medida em que trabalha primordialmente com a palavra ("signo ideológico por excelência”) e como um dos lugares de circulação e atuação de ideologias, institucionaliza códigos de leitura e escrita e caracteriza-se como uma das instâncias deliberativas e executivas na institucionalização do 'literário', atuando na formação do gosto, que gerará e moldará as necessidades do mercado da leitura (MAGNANI, 1989, p. 02).

${ }^{4}$ Anárquicas no sentido de que não precisam estar submetidas aos sistemas de valores e controle da crítica ou da academia, considerando "a desordem própria da construção do repertório de leitura dos adolescentes” (BRASIL, 2006, p. 61). 
Ao formador de leitores críticos de textos literários competiria também, em conformidade com o discurso acadêmico veiculado nos escritos de Rangel (2003), compreender que

o acesso livre a uma biblioteca com bom acervo é fundamental. Esse espaço pode ser utilizado também para eventos relacionados à leitura, como a conversa com um escritor convidado (os alunos ficarão contentes em receber um escritor vivo, já que a maioria dos que eles estudam estão mortos), a semana do livro, etc. (BRASIL, 2006, p. 81).

Além de tudo isso, o formador de leitores críticos de textos literários deveria ser capaz de investir toda a sua competência e criatividade na abordagem de um gênero que veio sendo costumeiramente ignorado na Educação Formal de jovens nos anos finais da Educação Básica: a poesia. No discurso em causa, seria esse sujeito docente quem poderia promover ações a partir das quais o leitor-aluno pudesse "olhar para a arquitetura do poema nas suas diferentes dimensões" (BRASIL, 2006, p. 74). Para isso, duas orientações fundamentais foram dadas:

a exploração dos efeitos de sentido produzidos pelos recursos fonológicos, sintáticos, semânticos, na leitura e na releitura de poemas poderá[ria] abrir aos leitores caminhos para novas investidas poéticas, para muito além desse universo limitado - temporal e espacialmente - de formação. [...] É[seria] importante, para isso, ampliar na escola o circuito de poemas e poetas, quem sabe buscando novas formas de circulação social de poemas como jornais, revistas (impressos e digitais), e mesmo em outros meios audiovisuais, que, em dobradinha com livros de poemas, permitiriam ver e entender a poesia como uma prática social integrada à vida cotidiana (BRASIL, 2006, p. 74-75)

Fundamentando todas essas ações, então esperadas do formador de leitores críticos de textos literários, estaria, segundo o discurso aqui estudado, o entendimento de que a leitura não é um processo passivo (Cf. BRASIL 1999b, 2002, 2006) e, que, portanto, no que se refere ao trato com o texto literário na sala de aula, o aprendiz não meramente decifraria passivamente sentidos e significados impostos. Posicionamento este em conformidade com o discurso acadêmico nacional - como o veiculado nas publicações de Walty (in. PAULINO; WALTY, 1994), comotambém com fontes internacionais que ecoam nesse posicionamento, como os trabalhos de Giasson (2004) - para quem seria necessária uma ruptura com o tradicional entendimento de que ler é um processo passivo e escrever, ativo -; e Mello (1999) - para quem "todo o acto de leitura compreende movimentos de subjectivação (compreensão intuitiva) e objectivação (validação de inferências), que podem ocorrer em simultâneo ou não (MELLO, 1999, p. 226)", que caracterizariam uma leitura ativa. 
No que se referia às práticas pedagógicas autorizadas para o sujeito docente, objetivado no discurso aqui analisado, cabe destacar que para ocupar uma centralidade como agente de uma mudança na educação formal ele deveria estar ciente de que estava inserido em um processo de mudança no qual sua ação seria essencial. Isto porque "as rupturas efetivas de paradigmas dependem sem dúvida da conscientização e da vontade de mudar dos profissionais envolvidos, sem mencionar uma adequada transposição das ideias propostas no plano teórico para a prática (BRASIL, 2002, p. 85)". Desse modo, no que se refere à avaliação, espera-se do sujeito docente desejado uma concepção de avaliação que,

diferentemente do que ocorre no ensino tradicional, privilegia-se [no novo projeto pedagógico para o Ensino Médio] a avaliação do processo de aprendizagem como um todo, durante o seu desenvolvimento. Em função disso, ao propor determinada atividade, o professor precisa ter muita clareza sobre suas intencionalidades bem como sobre os critérios que utilizará para avaliar seus resultados (BRASIL, 2002, p. 84).

Nesses termos, no discurso em questão, o sujeito docente desejado seria aquele que soubesse "valorizar os ganhos que o estudante obteve ao longo de seu processo de aprendizagem, baseando-se nas matrizes de competências e habilidades, que exigem um outro olhar sobre o ensino" (BRASIL, 2002, p. 84).

Para além das ações pedagógicas a serem operacionalizadas pelo formador de leitores críticos de textos literários, o discurso analisado fabrica, concomitantemente às prescrições para a atuação no ensino médio, a formação desejável para o indivíduo que aspirasse a ocupar a posição de sujeito docente de Língua Portuguesa para o trabalho com a leitura literária. Assim sendo, a escola desse "novo projeto educacional", pensado para os anos finais da Educação Básica, exigiria

uma formação literária dos professores de Português, sobretudo no âmbito da proximidade com a pesquisa e, consequentemente, do vínculo com a universidade, em percurso de mão dupla, já que essa não pode jamais esquecer seu compromisso com a educação básica. Além de mediador de leitura, portanto leitor especializado, também se requer do professor um conhecimento mais especializado no âmbito da teoria literária (BRASIL, 2006, p. 75). [Grifos nossos]

Finalmente, cabe destacar que, no discurso aqui analisado, não é só o indivíduo que almeja ocupar a posição de professor de Língua Portuguesa para o trabalho com a leitura literária quem deveria ser objeto da formação acima mencionada. Também o professor em exercício deveria fazê-lo, como partedochamadoprocesso de educação continuada.Afinal, sesecentrassem 
as reflexões "no universo escolar, tomando como referência as últimas propostas para o ensino médio, certamente esbarraremos [esbarraríamos] em resistências às mudanças que estão [estariam] profundamente relacionadas à formação geral e específica de professores (BRASIL, 2002, p. 85)". Em sendo assim, orienta-se sobretudo o professor atuante há mais tempo (mas não somente) quea "autoconsciência" constitui um dos três As 5 que comporiam tal processo identitário (BRASIL, 2002, p. 85). Isso porque,

em última instância, tudo se decide no processo de reflexão que o professor leva a cabo sobre sua própria ação. [A “autoconsciência”] é uma dimensão decisiva da profissão docente, na medida em que a mudança e a inovação pedagógica estão intimamente dependentes desse pensamento reflexivo (NÓVOA apud BRASIL, 2002, p. 85).

Mais uma vez, tinha-se um ponto de continuidade com o discurso acadêmico, então sobre a formação de professores, tema sobre o qual os estudos de Nóvoa (1992; 1999; 2000) constituíam, naquele momento (e ainda hoje), uma vertente bastante considerada. Daí a estratégia de fazer as orientações acima mencionadas a partir de uma longa citação desse autor português, a respeito do processo identitário dos professores.

$\mathrm{Na}$ sequência, buscando evidenciar ao professor atuante sobre necessidadedeatençãoconstanteàatualizaçãoda formação, argumentavao pesquisador lusitano que:

a identidade não é um dado adquirido, não é uma propriedade, não é um produto. A identidade é um lugar de lutas e conflitos, é um espaço de construção de maneiras de ser e estar na profissão. Por isso é mais adequado falar em processo identitário, realçando a mescla dinâmica que caracteriza a maneira como se sente e como se diz. A construção de identidades passa sempre por um processo complexo graças ao qual cada um se apropria do sentido da sua história pessoal e profissional. É um processo que necessita de tempo. Um tempo para refazer identidades, para acomodar inovações, para assimilar mudanças (NÓVOA apud BRASIL, 2002, p. 85).

E para aqueles que, convencidos da necessidade "revisar" sua identidade docente no que se referia a ocupar a nova posição de sujeito docente de Língua Portuguesa para o trabalho com a leitura literária nos anos finais do chamado novo Ensino Médio, se sentissem desejosos de um parâmetro, a orientação final dos PCN+ de Língua Portuguesa era de que se considerassem as orientações de Perrenoud (2002), nas consagradas dez competências, apresentadas na figura abaixo:

${ }_{5} \mathrm{Na}$ argumentação proposta por NÓVOA (200o), os outros dois As seriam o A de Adesão e o A de Ação (Cf. NÓVOA, 20oo, P. 16). 
1. Organizar e dirigir situações de aprendizagem;

2. Administrar a progressão das aprendizagens;

3. Conceber e fazer evoluir os dispositivos de diferenciação;

4. Envolver os alunos em suas aprendizagens e em seu trabalho;

5. Trabalhar em equipe;

6. Participar da administração da escola;

7. Informar e envolver os pais;

8. Utilizar novas tecnologias;

9. Enfrentar os deveres e dilemas éticos da profissão;

10. Administrar sua própria formação contínua.

FIGURA 1: PCN+ LÍNGUA PORTUGUESA ENSINO MÉDIO:

As dez competências para ensinar propostas por Perrenoud (2002)

A alegação para que as teorizações de Perrenoud constituíssem uma diretriz na revisão da identidade docente era a de que ele era "um dos principais teóricos do desenvolvimento das matrizes das competências e habilidades na escola" (BRASIL, 2002, p. 85), as quais orientam todas as reformas educacionais que vêm ocorrendo, sobretudo nas América Latina, desde os anos 1990. Estando evidente aí mais uma forma de continuidade discursiva.

\section{CONSIDERAÇÕES FINAIS}

Neste artigo, teve-se acesso a uma caracterização detalhada do que se espera do sujeito docente demandado para o chamado novo "projeto de educação" pensado para o Brasil, a partir dos anos 1990. No que se refere ao trabalho com a leitura literária nos anos finais da chamada nova Educação Básica, esse sujeito foi nomeado como um formador de leitores críticos de textos literários, conforme consta nas Orientações Curriculares Nacionais, último dos documentos que compuseram a materialidade discursiva aqui estudada.

Como observado, o formador de leitores críticos de textos literários é uma posição de sujeito que exige determinadas posturas e convicções. Assim, o indivíduo que aspira ser professor de Língua Portuguesa para o trabalho com a leitura literária no novo Ensino Médio deverá se tornar uma pessoa mais consciente sobre o público para o qual leciona - os jovens -, mais esclarecida quanto aos objetivos do seu trabalho, menos preconceituosa, mais bem informada, atualizada, usuária de tecnologias, leitora... convertendo-se num perfil que, como se nota, exige muito mais que o mero abandono de abordagem do texto literário hoje desqualificada. 
Nesses termos, oformador de leitores críticos de textos literários em muito se afasta do professor de literatura demandado para o trato com texto literário no antigo Segundo Grau, agora tratado como o "velho projeto pedagógico" da Educação Formal. A transmissão de um saber legitimado sobre uma literatura canônica, o foco na literatura como sinônimo de identidade nacional e como modelo de emprego da língua materna, a fidelidade à historiografia literária e a preferência por uma abordagem estruturalista e, principalmente, a compreensão do aluno como mero receptor do saber "superior" que era a literatura... isso tem mais lugar na existência do sujeito docente objetivado no discurso aqui analisado. Nada disso pode fazer parte das ações e entendimentos do Professor de Língua Portuguesa dos anos finais da nova Educação Básica que deseja ocupar uma centralidade namudança da Educação Formal do país.

Todavia, o mais relevante na reflexão aqui apresentada não foi essa invenção de uma outra posição de sujeito a ser ocupada pelo autuais e futuros professores de português do ensino médio, quanto ao trabalho com o texto literário. O mais interessante, a meu ver, é constatar que, mesmo que o nome dessa posição seja em si razoavelmente novo, o que se espera desse sujeito é algo que há mais de trinta anos vem se constituindo por um emaranhado de continuidades discursivas de diversos campos do conhecimento, todos eles legitimados pela academia.

Nesse sentido, a pergunta curiosa, que seria um interessante objeto de reflexão para estudantes e professores dos cursos de formação de professores em Letras é se não são tão novos, nem exclusivos, os discursos que se articulam em torno do "novo" projeto para a formação dos leitores jovens de literatura do ensino médio. Ora, se são continuidades o que se verifica no que há de mais “inovador" em termos de prescrições pedagógicas para o trabalho com a leitura literária nesse nível de ensino,por que esse formador de leitores críticos de textos literários não se torna uma recorrência nas salas de aula de nível médio do país? Essa parece ser a questão sobre a qual os cursos de formação de professores de português têm se eximido de se dedicar... é a ela que temos que nos deter.

\section{REFERÊNCIAS BIBLIOGRÁFICAS}

AGUIAR, Vera Teixeira de; BORDINI, Maria da Glória. Literatura: a formação do leitor: alternativas metodológicas. Porto Alegre: Mercado Aberto, 1988.

AGUIAR E SILVA, Vítor. “Tese sobre o ensino do texto literário na aula de português. In: Diacrítica. Revista do Centro de Estudos Humanísticos. n.13-14. Braga: Universidade do Minho, 1998/1999. p. 23-31. 
ALMEIDA, Maria Cristina Alves de. As tecnologias da informação e comunicação, os novos contextos de ensino-aprendizagem e a identidade profissional dos professores. Tese (Doutorado em Educação). - Faculdade de Psicologia e Ciências da Educação, Universidade do Porto, 2006.

BRASIL. Constituição da Republica Federativa do Brasil. Brasília, DF: Senado Federal, 1988.

BRASIL. Lei de Diretrizes e Bases da Educação Nacional (LDBN): Lei N. 9·394/96. 2. ed. Rio de Janeiro: DP\&A, 1999a.

BRASIL. Ministério da Educação. Secretaria de Educação Média e Tecnológica. Parâmetros Curriculares Nacionais: ensino Médio. Brasília: Ministério da Educação, 1999b

BRASIL. Ministério da Educação. Secretaria de Educação Básica. PCN+ Ensino Médio: Orientações Educacionais Complementares aos Parâmetros Curriculares Nacionais. Linguagens, Códigos e suas Tecnologias. Brasília: Ministério da Educação, 2002.

BRASIL. Ministério da Educação. Orientações curriculares para o ensino médio. Linguagens, códigos e suas tecnologias / Secretaria de Educação Básica. - Brasília: Ministério da Educação, Secretaria de Educação Básica, 2006.

BUARQUE, Cristovam. A aventura da universidade. 2. ed. São Paulo: Editora da Universidade Estadual Paulista, Rio de Janeiro: Paz e Terra, 2000.

CEIA, Carlos. Ser professor de literatura. In.: MELLO, Cristina; SILVA, Antonino; LOURENÇO, Clara Moura; OLIVEIRA, Lúcia; ARAÚJO E SÁ, Maria Helena (Orgs.). Didácticas das línguas e literaturas em Portugal: contextos de emergência, condições de existência e modos de desenvolvimento. Actas do I Encontro Nacional da SPDLL. Coimbra: Pé de Página, 2002. p. 33-39.

CHARTIER, R. A ordem dos livros: leitores, autores e bibliotecas entre os séculos XIV e XVIII. Tradução de Mary Del Priore. Brasília: Editora Universidade de Brasília, 1994.

CHARTIER, Roger. Práticas de leitura. São Paulo: Estação Liberdade, 1997.

COSSON, Rildo. Letramento literário: teoria e prática. São Paulo: Contexto, 2007.

COSTA, Leonardo Figueiredo. “Um estudo de caso sobre a mediação cultural”. Disponível em www.cult.ufba.br/enecult2009/19356.pdf. Consulta em 10/10/2009.

CURY, Maria Zilda. A historiografia literária em questão. In: PAULINO, Graça; WALTY, Ivete (Orgs). Teoria da literatura na escola: atualização para professores de I e II graus. Belo Horizonte, MG: Editora Lê, 1994. p. 55-68.

DELORS, Jacques. Educação: um tesouro a descobrir. Relatório para a UNESCO da Comissão Internacional sobre a educação para o século XXI. 5. ed. Tradução de José Carlos Eufrázio. São Paulo: Cortez; Brasília, DF: MEC: UNESCO, 2001.

DELORS, Jacques (Org.). A educação para o século XXI: questões e perspectivas. Tradução de Fátima Murad. Porto Alegre: Artmed, 2005. 
DEMO, Pedro. Educar pela pesquisa. 6a ed. Campinas, SP: Autores Associados, 2003.

DINIZ-PEREIRA, Júlio Emílio. Formação de professores: pesquisa, representações e poder. 2. ed. Belo Horizonte: Autêntica, 2006.

EVANGELISTA, Aracy Martins. "Algumas reflexões sobre a relação literatura/escola”. Disponível em www.anpede.org.br/reunioes/24/Too8587950265.doc . Acesso em 02/05/o6.

EVANGELISTA, Aracy Alves Martins. Escolarização da literatura entre ensinamento e mediação cultural: formação e atuação de quatro professoras. 2000. $294 \mathrm{f}$. Tese (Doutorado em Educação) - Faculdade de Educação, Universidade Federal de Minas Gerais, Belo Horizonte, 2000.

FISCHER, Rosa Maria Bueno. Foucault e a análise do discurso em educação. Cadernos de Pesquisa, n.114, novembro de 2001. p. 197-223.

FOUCAULT, Michel. A ordem do discurso: aula inaugural do Collège de France, pronunciada em o2 de dezembro de 1970. Tradução de Laura Fraga de Almeida Sampaio. 2. ed. São Paulo: Edições Loyola, 1996.

FOUCAULT, Michel Arqueologia do saber. Tradução de Luiz Felipe Baeta Neves. Rio de Janeiro: Forense universitária, 1995a.

FREITAS, H.C.L. Certificação docente e formação do educador: regulação e desprofissionalização. Educação E Sociedade, Campinas, v. 24, n. 85, p. 1095-1124, dez. 2003.

FREITAS, H.C.L. A (nova) política de formação de professores: a prioridade postergada. Educação E Sociedade, Campinas, vol. 28, n. 100 - Especial, p. 1203-1230, out. 2007

GARCIA, Carlos Marcelo. Formação de professores: para uma mudança educativa. Tradução de Isabel Narciso. Porto: Porto Editora. 1999.

GARCIA, Carlos Marcelo. Formación del profesorado: para el cambio educativo. Barcelona: PPU, 1994

GARCIA, Maria Manuela Alves. Pedagogias críticas e subjetivação: uma perspectiva foucaultiana. Petrópolis, RJ.:Vozes, 2002.

GAUTHIER, C. et.al. Por uma teoria da Pedagogia: pesquisas contemporâneas sobre o saber docente. Tradução de Francisco Pereira. Ijuí: Ed. UNIJUİ, 1998.

GERALDI, João Wanderlei. (Org.). O texto na sala de aula. São Paulo: Ática, 2003.

GIASSON, Joycelyne. La Lecture: de La théorie à la pratique. Adaptation réalisée par Tessa Escoyez. 2a ${ }^{\mathrm{a}}$.ed. Bruxelles: Gaëtan Morin Editeur; 2004; Montreal: De Boeck, 2003.

GREGOLIN, Maria do Rosário. Foucault e Pechêux na análise do discurso: diálogos e duelos. 3. ed. São Paulo: Editora Claraluz, 2007. 
HOUDART, Violaine. L'ouvre intégrale: aperçu historique et enjeux. In.: Le français aujourdhui. Paris, 1997, n. 117. p. 03-13.

LAJOLO, Marisa. Do mundo da leitura para a leitura do mundo. 6ạ. ed. São Paulo: Ática, 2002.

LAJOLO, Marisa. Literatura: leitores e leitura. São Paulo: Moderna, 2001.

LEAHY, Cyana. A educação literária e as políticas oficiais. In: PAULINO, Graça; COSSON, Rildo (Orgs.). Leitura literária: a mediação escolar. Belo Horizonte: Faculdade de Letras da UFMG, 2004.

LEITE, Ligia Chiappini Moraes. Invasão da catedral: literatura e ensino em debate. Porto Alegre: Mercado Aberto, 1983.

MAGNANI; Maria do Rosário Mortatti. Leitura, literatura e escola. São Paulo: Martins Fontes, 1989.

MARTINS, Aracy; CORRÊA, Hércules. O jogo dos saberes literários (Apresentação) In.: PAIVA, Aparecida; MARTINS, Aracy; PAULINO, Graça; CORRÊA, Hércules; VERSIANI, Zélia. Literatura: saberes em movimentos. Belo Horizonte: Ceale, Autêntica, 2007.

MELLO, Cristina. O ensino da literatura e a problemática dos gêneros literários. Coimbra: Almedina, 1998.

MELLO, Cristina. Leitura e memória literária. In.: MELLO, Cristina (Coord.). I Jornadas científico-pedagógicas de português. Coimbra: Almedina, 1999. p.219-228

NÓVOA, António. et. al. Os professores e sua formação. Tradução de Graça Cunha, Cândida Hespanha, Conceição Afonso e José António de Sousa Tavares. Lisboa: Dom Quixote, 1992.

NÓVOA, António. Profissão professor. 2. ed. Tradução de Irene Lima Mendes, Regina Correia e Luísa Santos Gil. Porto: Porto Editora, 1999.

NÓVOA, António et.al. Vidas de professores. 2.ed. Tradução de Maria dos Anjos Caseiro e Manuel Figueiredo Ferreira. Porto: Porto Editora, 2000.

PARAÍSO, Marlucy Alves. Currículo e mídia educativa brasileira: poder, saber e subjetivação. Chapecó: Argos. 2007.

PAULINO, Graça. Letramento Literário: cânones estéticos e cânones escolares. CaxambuMG: ANPED. Texto encomendado: GT 10 - Alfabetização Leitura e Escrita. Texto eletrônico, 1999. 17 p.

PAULINO, Graça; COSSON, Rildo (Orgs.). Leitura literária: a mediação escolar. Belo Horizonte: Faculdade de Letras da UFMG, 2004.

ROSIER, Jean-Marie. Désacraliser la littérature. In.: Chiers Pédagogiques. n.313. Paris: avril, 1993, p. 48-49. 
PAULINO, Graça; WALTY, Ivete; FONSECA, Maria Nazareth; CURY, Maria Zilda. Tipos de textos, modos de leitura. Belo Horizonte: Formato Editorial, 2001.

RANGEL, E. “O. Letramento literário e livro didático de língua portuguesa: 'os amores difíceis'. In.: PAIVA, Aparecida; MARTINS, Aracy Alves; PAULINO, Graça; VERSIANI, Maria Zélia (Org.). Literatura e Letramento: espaços, suportes e interfaces. Belo Horizonte: Autêntica/Ceale/FAE/UFMG, 2003.

SARGENTINI, Vanice; BARBOSA, Pedro Navarro (orgs). Foucault e os domínios da linguagem: discurso, poder, subjetividade. São Carlos: Claraluz, 2004.

SILVA, Ezequiel Teodoro da. Leitura E realidade brasileira. Porto Alegre: Mercado Aberto, 1983.

SOARES, Magda. A escolarização da literatura infantil e juvenil. In.: MARTINS, Aracy; BRANDÃO, Heliana Maria Brina; MACHADO, Maria Zélia Versiani (Orgs). Escolarização da leitura literária. Belo Horizonte: Autêntica, 1999. p. 17-48.

WALTY, Ivete Lara Camargos. Leitura literária em tempos de crise. In.: http://www.ich. pucminas.br/posletras/A\%2oleitura\%2oliteraria\%2oem\%2otempos\%2ode\%20 crise.pdf . Acesso em: 18 mar. 2009a.

WILLIGEN, John Van. Applied Anthropology: An Introduction. South Hadley: Bergin and Garvey Publishers. 1993.

ZILBERMAN. Regina. A leitura e o ensino da literatura. São Paulo: Contexto, 1988.

ZILBERMAN, Regina (Org.). A leitura na Escola . In: Leitura em Crise na Escola: as alternativas do professor. Porto Alegre: Mercado Aberto, 1986.

ZINANI, Cecil Jeanine Albert; SANTOS, Salete Rosa Pezzi dos. Parâmetros Curriculares Nacionais e ensino de literatura. In.: PAULINO, Graça; COSSON, Rildo (Orgs.). Leitura literária: a mediação escolar. Belo Horizonte: Faculdade de Letras da UFMG, 2004, p. 63-74. 